\title{
A Grounded Theory Approach towards Conceptualizing CIS for Heterogeneous Work Communities
}

\author{
Nallini Selvaraj \\ School of Engineering and Information Sciences \\ Middlesex University \\ London, UK. \\ ++44 (0)20 84114218 \\ n.selvaraj@mdx.ac.uk
}

\author{
Bob Fields \\ School of Engineering and Information Sciences \\ Middlesex University \\ London, UK \\ +44 (0)20 84112272 \\ b.fields@mdx.ac.uk
}

\begin{abstract}
The notion of Common Information Space (CIS) is an area that has been gaining attention in the field of Computer Supported Cooperative Work (CSCW) over the last few years. This paper discusses one aspect of the investigation being undertaken to develop the conceptualization of CIS pertaining to heterogeneous work communities. This is based on empirical study of collaborative decision making involving different work communities in an airport of the air traffic control setting. The theory development is founded on the Grounded Theory approach. We present some of the findings of the ongoing analysis. In particular we discuss how the Grounded Theory methodological process has been adapted to this investigation by presenting illustrations of emergent theory development at the theoretical coding phase of the process.
\end{abstract}

\section{Categories and Subject Descriptors}

H.5.3 [Group and Organization Interfaces]: Computersupported cooperative work, Theory and models

\section{General Terms}

Human Factors, Theory

\section{Keywords}

Grounded Theory, Computer Supported Cooperative Work, Common Information Space

\section{INTRODUCTION}

Complex work settings such as air traffic control systems are collaborative work settings that encompass multiple work communities. In order to manage the complexity of work involved, the tasks to be performed in the work process are decomposed and distributed among multiple personnel and different work communities [1]. Also, the complexity of the work process necessitates that people work together cooperatively and not in isolation. In such settings personnel of a work community are formally bound to one another within

(C) The Author 2009.

Published by the British Computer Society the community and to personnel in other work communities through collective pursuit of achieving common goals.

In the field of Computer Supported Cooperative Work $(\mathrm{CSCW})$, one concept that has been gaining attention of late to support collaborative work is that of Common Information Space (CIS). The value of utilizing this notion has been attributed to its focus on the interrelationship between information, actors, artifacts, and cooperative work [2], thereby focusing on a larger unit of analysis. Although various researchers have addressed the development of this notion, research in this area is still in its infancy especially with regards to CIS for collaborative work across heterogeneous work communities.

The focus of this investigation is to contribute to the development of the theory of CIS by taking a work centric view rather than a technology centric stand. This is achieved by adopting an exploratory approach to generate a theoretical framework. The framework is aimed at facilitating analysis that can inform the development of technology for creating CIS.

This research work takes on the Grounded Theory approach for conducting the investigation. We provide here a description of how the methodological process has been employed in this investigation through illustrations of theoretical concepts generated during the analysis. The aspect of work process that forms the focus for this investigation is that of collaborative decision making in heterogeneous work communities. The perspective adopted towards decision making in this study was more inclined to explore its social nature rather than the typical cognitive aspect of it. The investigation is in progress and its depiction here is with the intention of illustrating how such an analysis of real world work process can be used to generate theories that act as foundation for design of systems employed in collaborative work settings. In this paper we focus on illustrating the analytical process involved in developing theories or frameworks. We do not aim to conclude the paper by presenting a concrete theory or framework or any 'implications for design' but focus on presenting a process for eliciting relationships between elements of a collaborative work process in order to develop the notion of CIS.

\section{THE CONCEPTION OF CIS}

In the field of CSCW research has been undertaken in the past few years to support articulation of cooperative work through the construction of information spaces. These spaces are viewed as communication spaces or interaction spaces [3]. In the case of distributed settings and more so in the case of a dynamic environment apart from sharing information it is also necessary that the information is interpreted in the way it is 
supposed to be and people sharing the information have a common interpretation of it or at least common enough interpretation of it to coordinate their work.

In the last few years various researchers in this area have tried to build on the concept of such an information space. Bannon and Bodker [4] address the dual nature of a CIS and illustrate that it is both open and closed which leads to problems in its characterization. Also, they illustrate by presenting different work settings how the mechanics to support holding information in common varies with the setting - when CIS's are constituted for people who are co-present in time and space or for those across time and space boundaries. Bannon [5] on the other hand is skeptical about such a concept of information space and calls for a clarification of the efficacy of such a space in cooperative work. Randall [6] is of the view that "we are a long way from finding the generic properties for CIS and the very notion of CIS is underspecified". He emphasizes the need to understand the organizational context in order to understand the conditions in which the CIS would have to operate. Bertleson and Bodker [7] call for a broader focus on the conceptualization of CIS by shifting the focus from co-located control room like settings to cooperation in geographically dispersed settings of waste water treatment. Based on empirical study of a medical care setting Reddy and his colleagues [8] investigate how shared information is incorporated into the diverse everyday work practices of an intensive care unit by using the idea of CIS. They propose different representations of the same information to facilitate better coordination of heterogeneous work.

Bossen [9] presents seven parameters as a framework for analyzing and characterizing CIS based on an ethnographic study of a hospital ward. Fields and his colleagues [10], regard the airport setting not as a CIS but as a constellation of overlapping interdependent CISs that are articulated through boundary objects. Rolland [11] conducted studies on well planning in an oil and gas company to address the nature and dynamics of a CIS across heterogeneous contexts. They illustrate that in such settings a CIS is a short-lived arrangement that constantly needs to be re-negotiated and hence is always in the making. Also, attempts to integrate and cut across geographically dispersed communities of practice and heterogeneous collections of information are likely to produce new instances of fragmentation. Munkvold and Ellingsen [12] explore how CIS is achieved in practice by drawing on the notion of trajectories and develop a perspective that emphasizes its situated, temporal and negotiated nature.

From the above review of the work conducted in this area, we can infer that the concept is still in the making with quite varied and dispersed views on the characterization of CIS. The investigation being currently undertaken is an attempt to contribute to the development and clarification of the notion of CIS. This is done by studying how people from different work communities collaborate to manage various dependencies arising in the course of accomplishing tasks leading to a common goal. Also, from the review it was observed that most of the conceptualization of CIS was based on ethnographic studies. We feel that a more rigorous process of investigation is required to develop the notion of common information space, which is being addressed in this paper.

\section{GROUNDED THEORY APPROACH}

We present a brief overview of the Grounded Theory process as a detailed explanation is beyond the scope of this paper. This research method was developed by Glaser and Strauss [13] to arrive at a theory of a phenomenon grounded in a systematically gathered and analyzed data. This research method is useful in eliciting context based descriptions and explanations of a phenomenon. Compared to other qualitative research methods, Grounded Theory places emphasis on continuous interplay between data collection, analysis, and theory development.

The analysis begins with coding of data in order to derive categories, then drawing relationships between categories and eventually deriving core categories. The core category is abstraction of the focus of study that contributes towards theoretical development. The main aspects of Glaser's approach are that of constant comparison, theoretical sampling, theoretical coding, and theoretical memos. Constant Comparison is the process of comparing incidents to incidents and/or to concepts as the researcher goes through the data. At the initial stages this process is aimed at identifying patterns that could be formed into categories and in later stages to associate these theoretical constructs. Theoretical Sampling is the process of data collection where codes elicited from the start of data collection direct collection of further data which are then coded and the process continues until saturation is achieved. Theoretical Sampling is continued until the very end of the process all through the conceptualization process until the researcher has identified the core category and after that to strengthen that category. Theoretical Coding is the process of conceptualization where relationships between categories as well as between categories and their properties are drawn in the form of hypothesis to be integrated in the theory. Theoretical Memos are written records of the researcher's abstraction of the analysis which could be reflections, meanings ascribed, theoretical explanations of relationships, etc. Memo writing is an important aspect of theory generation which takes place throughout the theory development process right from its inception to the end.

The Grounded Theory process is both inductive and deductive. Inductive, in that instead of starting with a hypothesis or theory relevant theoretical concepts are allowed to emerge from the data during the coding and categorization process. Deductive work in grounded theory is used to derive from initial codes as to where to go next in order to sample for more data to generate the theory [14]. This is a cyclic process where the researcher goes back and forth between induction and deduction.

Over the years Grounded Theory has evolved into two fundamentally different approaches; the original Glaser and Strauss's [13] version that stresses on interpretive, contextual, and emergent nature of theory development, and other Strauss and Corbin's [15] version which advocates highly systematic and complex coding techniques and deductive data analysis [16]. In this investigation we have tried to follow Glaser's approach as closely as possible. In such an investigation the interpretive aspect of the process is left much to the proficiency of the researcher. Given the complexity involved in the analysis of such a systematic approach sometimes tools are required to aid the conceptualization process. To address this we have adapted one of Strauss's techniques at a later stage in this research to augment the conceptualization process. In this paper we present how such an integrated approach to employing Grounded Theory aids interpretation of relations between theoretical constructs derived from the data analysis. 


\subsection{Data Collection}

\subsubsection{Role of the Researcher}

The researcher is the principal device for collecting data and this includes the researcher's interpretation of the data collected. Hence, one issue that has to be addressed here is the plausible researcher bias affecting the credibility of the investigation. It is important for the researcher to be sensitive about his/her biases and judgement. The researcher embarked on this investigation after having identified the area of interest and conducted a literature review in relevant subjects in order to arrive upon the research questions. This did not result in suggesting a hypothesis but helped the researcher to identify a gap in the area of interest which was fabricated into the research questions. Besides that the researcher did not have any prior knowledge or experience in the field that would generate pre-conceived views and pre-formulated judgement about the phenomenon being investigated. Because of the safety critical nature of the study environment the researcher could not be a participant in the work process. Hence, the observational studies were conducted as a novice and an outsider. Therefore the data collected were to a large extent perceived from the participant's point of view and any interpretation made by the researcher was verified with the participating personnel. Also, the participants were briefed on the role of the researcher in their work place. Besides justifying the researcher's presence this is believed to have made them less guarded in their discussions with the researcher. The researcher embarked on this investigation without a preconceived theory in mind and through out the research process has remained conscious of the potential effect of bias.

\subsubsection{Study Site}

The domain of interest for this research is that of the work process of Air Traffic Control (ATC) and in particular the work taking place in an airport. The study is being conducted in a medium-sized single runway airport in the UK. The studies have been mainly undertaken in the control tower of the airport focusing on the working of actors with each other within the control tower as well as with those from other work communities. The tower is staffed by two controllers (Ground Controller and Tower Controller) and an Assistant. Each controller is responsible for tactical control of aircraft, on the apron area and taxiways (Ground Controller) and on the runway and surrounding airspace (Tower Controller). The controllers have to liaise with various agencies in and around the airport such as airlines agency, apron control, approach control, emergency services, etc. The role of the assistant is best described in the following transcript from the field note: $\mathrm{He} / \mathrm{sh}$ he has to coordinate various activities with both the controllers in the tower and with other agencies in the airport such as accident services, maintenance services, weather office, apron management, approach control in London, pilot enquiries etc. Their primary function is to ensure that the safety of aircraft is maintained by providing the required information to both controllers at the right time.

\subsubsection{Sampling Method}

Grounded Theory methodology prescribes analysing the data concurrently with data gathering. Therefore, an initial sample was selected once the research phenomenon was identified and an initial research question was formulated; how holding information in common concerns the articulation of collaborative work and decision making process in a work setting. After the initial sample selection further sampling was determined from the findings of the preliminary investigation.
In this case, we started with a sample of one work community (controllers in the control tower) where preliminary observational studies and interviews were conducted. The first set of data was collected which lasted over fifteen days spread across two months with around four hour sessions during every visit. The questions raised from the analysis directed further sampling. For the next set of studies the same work community was retained but the sampling was extended to involve more aspects of the phenomenon being investigated. For example, the first visits to the field focused on the collaboration between actors both within the control tower and to some extent collaboration with other work communities in the airport. As the data analysis progressed the focus digressed to that between mostly between work communities and also the decision making involved in the work process.

Every member in the work community (controllers in the control tower) was included in the initial sample. This was because the number of positions in the work community was limited to three. However, these positions were taken on by different personnel. While conducting the studies the researcher encountered six personnel taking up these positions at different times. At the initial stage the aim was to gain an understanding of the work environment and to identify relevant work and social processes. It was found that the work of the personnel in the three positions was tightly integrated with each other's while working as a community as well as to some extent while having to collaborate with other work communities. Hence, it was decided that including all of them in the sample would only enrich the data collection. All six personnel were retained for further sampling with only the aspects of the work process being extended. Each of the six personnel was observed during the studies and interviews were conducted with each of them when they took up their respective positions.

\subsubsection{Data Collection Techniques}

\subsubsection{Observation}

The data collection commenced with formal and informal observational studies in the site, which continued through out the data collection process. Observation could focus on either the environment or people or both. In this research both environment and people are observed. The researcher recorded both the social and environmental context as well as individual and group behavior. This involved taking notes of observed phenomenon and informal discussions with personnel about the observations made. The field notes contained information on environmental setting, behaviour of people, work practices, and questions arising from observations made. Besides this the researcher also collected audio recordings, photographs, artefacts and organizational documents from the site.

\subsubsection{Interviews}

The data was collected by conducting semi-structure interviews with personnel in the work community consisting of openended semi-structured questions. Concurrent protocols were also employed where participants were asked to talk through what they were doing while they were working. All the interviews and verbal protocols were recorded and were later transcribed into text for analysis.

\subsubsection{Secondary Data Source}

Besides getting first hand data from the site, several secondary sources of data were identified. This included organization and technical documents, studies conducted by others in the area, literature on the field site, etc. 


\subsection{Analysis - An Integrated Approach}

The data collected through various techniques mentioned in the above section were transcribed for coding and analysis. The analysis of data took place simultaneously with data collection, with the researcher going back and forth between data collection and analysis to address the questions raised during each iteration and to strengthen the concepts being developed. The data analysis was conducted using the qualitative data analysis software of Atlas.ti 5.4. It was employed as a tool to store interview transcripts, field notes, memos and other documents, code and categorize data, generating reports, and create models of conceptualizations.

\subsubsection{Substantive Coding}

The first step of the analysis is open coding. The data was analyzed by assigning labels to concepts identified as the researcher went through the data line by line. This was done by identifying observations or occurrences (incidents) by asking neutral questions as prescribed by Glaser [17] such as

- What is the data a study of?

- What category or what property of what category does this incident indicate?

\section{- What is actually happening in the data?}

Also, the incidents were compared to other incidents and/or concepts wherever possible as the researcher analyzed the data. As open coding progressed categories were developed where patterns of similar incidents were abstracted by attributing a conceptual name to it. The data analysis has resulted in nearly 760 codes until now which were categorized into 63 categories. Not all the codes were included in the category development and were delimited based on their relevance to the investigation as the analysis progressed.

\section{Table 1. Theoretical Families Employed}

\begin{tabular}{|l|l|}
\hline Relationship & Coding Families \\
\hline is-context-for & CONTEXT \\
\hline $\begin{array}{l}\text { is-cause-of, is-trigger-for, is- } \\
\text { source-of }\end{array}$ & CAUSE \\
\hline $\begin{array}{l}\text { is-causal-condition-for, } \\
\text { is- intervening-condition-for }\end{array}$ & CONDITION \\
\hline $\begin{array}{l}\text { has-effect-on, leads-to, } \\
\text { is-dependent-on }\end{array}$ & COVARIANCE \\
\hline $\begin{array}{l}\text { is-outcome-of, is-function-of } \\
\text { is-consequence-of }\end{array}$ & CONSEQUENCE \\
\hline $\begin{array}{l}\text { is-maneuver-for, is-managed- } \\
\text { by, is-mechanism-for, is- } \\
\text { means-of, is-strategy-for, is- } \\
\text { through }\end{array}$ & STRATEGY \\
\hline is-a, is-form-of, is-type-of & TYPE \\
\hline is-aspect-of, is-property-of & DIMENSION \\
\hline is-level-of & DEGREE \\
\hline is-reciprocity-to & INTERACTIVE \\
\hline is-stratification-of & MAINLINE \\
\hline
\end{tabular}

\subsubsection{Theoretical Coding}

As category development progressed the researcher started to determine the relationship between categories and their properties in order to generate conceptual ideas through theoretical coding. This was captured in the form of memos. To draw relationship between categories the theoretical coding families recommended by Glaser [14] were employed. The first of these families and the one most utilized until now for theoretical coding in this research is that of "The Six C's"Causes, Contexts, Contingencies, Consequences, Covariance and Conditions. Besides these six C's some of the other theoretical coding families were also included depending on the relationships emerging from the data. The following table presents the relationships generated between categories and their properties until now in this investigation and the coding families they belong to.

"Context" is the ambiance in which the phenomenon occurred. "Cause" is the reason, source or explanation for the occurrence of the phenomenon. "Condition" or qualifier is an intervening variable. "Covariance" is a correlation where one category changes with another [15]. "Consequence" is the anticipated or unanticipated result of the phenomenon and is dependent on "Cause". "Means-Goal" is a sub-family of "Consequence" in that it is an anticipated consequence. "Strategy" is a conscious act to maneuver elements associated with the phenomenon. "Dimension" is parts of the phenomenon, dividing the whole into parts. "Type" is a variation of the whole phenomenon. "Degree" is the relative position of the phenomenon in a continuum. "Interactive" is the mutual effects between the phenomenon and another variable where the temporality of the interaction is not taken into account. "Mainline" is the societal aspects of the work process such as the social organization, social order, social interactions, etc.

\subsubsection{Conditional Relationship Guide}

Although these families have assisted the theoretical coding process in understanding and establishing relationships between categories and even though it was implemented using a qualitative data analysis software, the researcher was besieged by the number of categories developed and the relationships between them. In order to proceed with the conceptualization the researcher felt the need for a representation of the interrelationships between categories that would aid the development of theoretical explanations.

After much trial and error with using the software as well as ways of modeling through tabulation and diagrams, the researcher adapted the conditional relationship guide developed by Scott [18] to support the analysis. She suggests creating a matrix to understand the relationship among categories by asking [19] investigative questions of what, when, where, how, and with what result of consequence. The following describes the way the questions are employed to create the conditional relationship guide matrix, as replicated from [18]

- What is [the category]? (using participants' words helps avoid bias)

- When does [the category] occur (using "during..." helps form the answer)

- Where does [the category] occur? (using "in..." helps form the answer)

- Why does [the category] occur? (using "because..." helps form the answer)

- How does [the category] occur? (using "by..." helps form the answer) 
- With what consequence does [the category] occur or is [the category] understood?

Scott then uses this guide to construct a reflective coding matrix as a relational hierarchy of major categories identified in the conditional relationship guide to develop and contextualize the core category.

In this investigation, the researcher has adapted only the conditional relationship guide to aid the conceptualization of relationships between categories. This was done by first employing the theoretical coding families to draw the relationship between categories. Then the conditional relationship guide matrix is created based on this. The matrix is subsequently reflected upon by asking the questions cited above to enhance the clarity of the relationships drawn and to verify the exhaustiveness of the categories related with respect the phenomenon of focus.

However, one should be careful while employing the above process because it could lead to an extensive number of category relationships. The researcher can overcome this by being constantly aware of not forcing the relationships and to allow it to emerge from the data. The researcher is also aware of Glaser's objection to such an approach of investigative questioning during theoretical coding, as it is considered to be forcing the theory instead of allowing it to emerge from the data. However, for this investigation, combining the two methods only facilitates the process of conceptualization by providing a comprehensive insight into the investigation. Also, the relations between the categories are not forced because the conditional relationship guide has been developed based on relationships drawn using the theoretical coding families and the investigative questioning is only used as a conceptualization enhancement instrument.

In the next section we present a depiction of such an analysis focusing on theoretical explanations rather than the lower level coding stages.

\section{FINDINGS}

While employing the technique of neutral questioning of the data during open coding, the researcher identified a phenomenon of interest to the investigation, that of "managing interdependencies". Crowston's [20] work on coordination theory in the field of business management also contributed towards the theoretical sensitivity of the researcher while generating concepts during the data analysis. Although Glaser does not prescribe reading literature in the relevant field before the theory seems sufficiently grounded and developed, he however suggests reading literature, but in a substantive field different from the research [14] in order to enhance the theoretical sensitivity of the researcher. Reading literature of other's work in different disciplines hence helps the emergent fit of concepts generated in this study and is not intended to replicate their stance.

In this section we present our findings in the form of theoretical concepts and their relationships with respect to this phenomenon of "managing interdependencies". During the initial coding and categorization process, categories were formed and relationships identified that relate to the decision making aspect of collaborative work. The analysis revealed that decision making is an important aspect of managing interdependencies. The three higher level categories of "situated decision making", "making informed decisions", and "deciding when?" seemed to play a pivotal role in managing various dependencies that arise between the work of personnel in the control tower and those in other work communities. Figure 1 depicts these categories and their relationships.
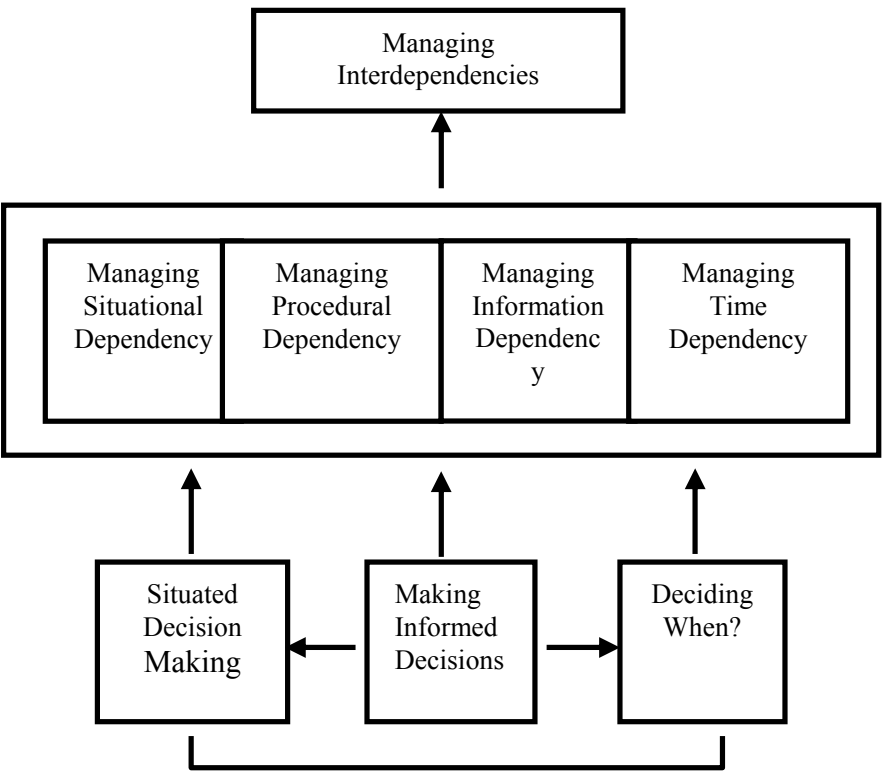

Figure 1. Higher Level Categories and their Relationships

The relationship between these concepts is discussed in the forthcoming sections.

\subsection{Dependencies in the Work Process}

"...No aircraft can go anywhere without a clearance. They need to know where to go basically and if you don't give them a point where to go to and where to go from and a route, they are in limbo. Basically that's what it is. You have to tell him (aircraft) where to go. Otherwise he (arriving aircraft) is going to come up to you (tower controller) and say 'what do I do? What stand am I in? Which way do you want me to go?"

The above transcript provides an illustration of the dependencies arising in management of aircraft movement in an airport. In order to manage safe and efficient movement of traffic in and out of the airport, the control tower has to work in conjunction with the activities of other work communities in and around the airport. The tasks to be performed by various communities are interdependent. The coding process revealed dependencies between the control tower and other work communities mainly that of Apron Control, Approach Control, Terminal Control, Maintenance Services_Workshop, Pilots (Aircraft \& Police Helicopter), Weather Office, CFMU, LFMU, Accident Services, Accounts Department, and Airport Authority. The level of dependency of the control tower on each of the other communities however varied based on the situation encountered. The coding also revealed four main types of interdependencies between these work communities: procedural dependency, information dependency, situation dependency and time dependency.

\subsubsection{Procedural Dependency}

Procedural dependency is the dependency between people and work communities that arises as a result of the procedures laid down by the organization which has to be followed to accomplish goals and perform tasks. The coding process revealed that this dependency is mostly in terms of actions to be performed and information requirements. Once the dependency was identified, the data was coded to identify how the 
procedural dependency was managed by people. Typically, this involves personnel performing actions in coordination with that of others. It also entails information transfer between personnel whose tasks are interdependent both within and between communities.

For example one of the procedural dependencies that were observed between the assistant in the control tower and the airport authority community is when the assistant is aware of any problem on the runway or taxiway, he/she has to telephone the airport authority and inform them about it.

\subsubsection{Information Dependency}

This dependency arises as a result of information requirements of tasks. Since the tasks to be performed in the work process are distributed among different personnel belonging to different work communities, the information required to perform tasks is also dispersed among these distributed personnel. The interdependencies in the tasks beget dependencies in information. From the codes generated it was identified that this dependency is mainly managed through the three main mechanisms of requesting information, sending information, and making changes to common information artefact as depicted in the following transcript:

For inbound and outbound aircraft, the parking gate number for the aircraft has to be written on the (flight progress) strip by the Assistant (to be given to the respective controller in the control tower). The parking gate number is provided by the Apron Control located elsewhere in the airport by feeding the information into a technical system that can be accessed by both the Assistant in the control tower and the liaising actor in the Apron Control. If the gate number is not available in the system, the Assistant has to telephone the Apron Control to find it.

\subsubsection{Situational Dependency}

This refers to the dependencies caused by the state of the work environment on people, tasks and resources. Since air traffic control is a dynamic environment people do not work under static conditions. The situation in the work process is changing continuously and the way personnel conduct their work has to cater to the changing circumstances. During the coding process different kinds of situations were identified which were classified as typical situation, atypical situation, and emergency situation. We will not go into the details of this classification here. However we would like to mention that different situation brought about different requirements and dependencies in the work process.

The analysis also revealed how people manage the different kinds of situations during the performance of various activities. When working in a typical situation, personnel follow the standard procedure prescribed by the organization to carry out the activities. However, when the situation deviates from normally expected circumstances to atypical situation such as information unavailability or system failure, they either follow the standard procedure or sometimes are prepared to face such situations by planning what actions should be taken by them in event of such a situation such as either by making use of other resources, delaying certain actions or getting help from other people. It was found that while acting under such conditions there was increased instruction transmission between people across different work communities, people tend to change the plan (of action) quickly, involve others in managing the situation, perform quick coordination with those who are involved, and also required high concentration.
When faced with a critical situation besides following the protocol, people working under such circumstances need to carefully monitor the situation, keep related personnel informed about the developing state of events which sometime requires lot of talking to each other, be aware of actions being taken so far so as to make informed decisions, all of which requires increased concentration on the part of the individual working under such a situation. It was also found that people need to be focussed as well as "think quickly on the spot" in order to change the plan quickly. Also, they need to communicate the change in plan to related personnel - "lot of talking on the phone" - in order to perform quick coordination. Personnel not only change the plan quickly but also "play by the rules" which helps those involved in managing the situation to have a common frame of reference while acting under such circumstances. The words within quotes are codes from the data analysis.

\subsubsection{Time Dependency}

Change in situation is inevitable in any traffic management system and so as well in air traffic control system. The rate of change in the work environment also causes certain dependencies in the way the tasks are performed in the work process. The work of personnel in the control tower is driven by the temporal aspect of the work domain to a considerable extent. This is illustrated in the following transcript from the field notes, the Assistant has to print the flight progress strip half an hour before the aircraft has to depart or arrive, put them in strip holders and place it on the corresponding controller's strip racks. Since air traffic control is a highly time critical environment with respect to safety and pecuniary aspects, this raises dependencies of temporal nature in the work process.

Some of the ways in which personnel were found to manage time dependency were (as depicted in the open coding): "deciding priority of actions to be performed", "a look-ahead of future events", "deciding course of action based on time constraint", etc.

In the next section we will describe the role played by the decision making process in managing the various dependencies mentioned above. This is illustrated by presenting the conditional relationship guide constructed for the three main phenomena identified with respect to decision making. As mentioned in section 3.3.3, the relationship between categories were established first using the theoretical coding families presented by Glaser, then the conditional relationship guide was constructed based on this to provide a structure to aid analysis. The labels within double quotes are in-vivo codes. The category labels highlighted in bold are the categories being presented in this paper.

\subsection{Situated Decision Making}

The format of the conditional relationship matrix is such that we answer the relational questions about each category listed in the first row. In this example, the focus is on the phenomenon of "Situated Decision Making". The answer to the first question What provides a description about the category elicited from the data. The transcript from an interview illustrating this description is presented within double quotes. "Situated Decision Making" signifies environmental condition or situation having a bearing on the decisions made by people. This could be past, present, and expected state of the work environment. 
The answer to the next three questions, When, Where, \& Why are aimed at identifying contextual conditions and boundaries in which the phenomenon is identified. The way this is adapted here is the relations belonging to the family CONTEXT (see table 1) are used to answer the question When, relations belonging to the families CAUSE and CONDITION are both used to answer the two question Why and Where. If there is any ambiguity in placing the categories then the researcher verifies or tries to comprehend the relationship based on the participant's view from the data. The fifth question How identifies the actions and interactions, which in this case are relations belonging to the family of STRATEGY and COVARIANCE. Finally, the last question is answered based on how the categories used to answer the previous questions relate as well as the relations belonging to the families CONSEQUENCE and MEANS-GOAL. Detailed presentation of the construction of the matrix is beyond the scope of this paper. Hence, we provide a brief explanation of the conceptualization here.

Table 2. Conditional Relationship Guide of Category: Situated Decision Making

\begin{tabular}{|l|l|}
\hline Category & \multicolumn{1}{|c|}{ Situated Decision Making } \\
\hline What & $\begin{array}{l}\text { Decision made by personnel influenced by the } \\
\text { state of elements in the operational } \\
\text { environment. } \\
\text { "It depends purely on the situation on what's } \\
\text { going on, how complex the traffic situation is" }\end{array}$ \\
\hline When & $\begin{array}{l}\text { Handling Dynamic Nature of Work, Managing } \\
\text { Time Critical Nature of Work }\end{array}$ \\
\hline Where & $\begin{array}{l}\text { Handling Typical Situation, Handling Atypical } \\
\text { Situation, Handling Emergency Situation, } \\
\text { Adapting to Change in Situation, Managing } \\
\text { Procedural Dependency }\end{array}$ \\
\hline Why & $\begin{array}{l}\text { Catering to Other's Requirements, Deciding } \\
\text { Course of Action, Deciding Individual Action, } \\
\text { Helping Others, Optimizing Task Performance, } \\
\text { Responding to Requests, Task Handover } \\
\text { Decisions, Deciding Priority of Action }\end{array}$ \\
\hline How & $\begin{array}{l}\text { Comprehension, Reacting, Anticipation, } \\
\text { Anticipatory Interactions, Applying Pre-Task } \\
\text { Knowledge, Decision Based on Current } \\
\text { Situation, Decision Based on Time Constraint, } \\
\text { Planning, "Making Informed Decisions" }\end{array}$ \\
\hline Consequence & $\begin{array}{l}\text { Deciding Course of Action, Exercising } \\
\text { Authority, Managing } \\
\text { Dependency, Managing Information } \\
\text { Dependency }\end{array}$ \\
\hline
\end{tabular}

In the example, the answer to the question when is that the decision making process takes place during situations that are ever changing and during situations where the timing of actions and tasks performed is critical to the successful functioning of the work process. The third question is where does "Situated Decision Making" occur? People make decisions while Handling Typical Situations, Handling Atypical Situations, and while Handling Emergency Situations. The next question is why does "Situated Decision Making" occur? It occurs to Cater to Other's Requirements to manage procedural dependencies and includes to Responding to Requests and to make Task
Handover Decisions, to Decide Individual Actions which is an aspect of Deciding Course of Action, to Decide Priority of Actions to be performed to manage time constraint in the work process, and to Optimize Task Performance. Answer to the question How depicts the ways in which "Situated Decision Making" takes place. The actors do this by applying Pre-Task Knowledge that is the procedural knowledge they hold, by Anticipation of Work Events, Anticipation of Other's Requirements, Anticipation of Other's Behavior, by Planning, by Anticipatory Interactions such as Verifying, Confirming, Verbal Notification, Announcing, etc. in order to be Prepared for Handling Anticipated Events, and also involving the category Decision Based on Expected Situation. Situated Decision Making also takes place by making Decision Based on Time Constraint as well as by Making Informed Decisions.

The last question is what is the consequence of "Situated Decision Making"? The consequence of the occurrence of this phenomenon has been identified to be Deciding Course of Action, Exerting Authority in the form of Giving Instructions and Giving Permissions to others to perform certain actions, Managing Situational Dependency which are the dependencies encountered while handling different Kinds of Situation as well as Managing Information Dependency.

Table 3. Conditional Relationship Guide of Category: Making Informed Decisions

\begin{tabular}{|c|c|}
\hline Category & Making Informed Decisions \\
\hline What & $\begin{array}{l}\text { Making Decisions based on information } \\
\text { available about the state of elements in the } \\
\text { operational environment. }\end{array}$ \\
\hline When & Handling Dynamic Nature of Work \\
\hline Where & $\begin{array}{l}\text { Managing Time Constraint, Decision for } \\
\text { Response to Requests, Helping Others, } \\
\text { Reacting, Adapting to Change in Situation, } \\
\text { Task Handover Decision, Exerting Authority, } \\
\text { "changing the plan quickly" }\end{array}$ \\
\hline Why & $\begin{array}{l}\text { Adapting to Change in Situation, Catering to } \\
\text { Other's Requirements, Deciding Course of } \\
\text { Action, Optimize Task Performance, Giving } \\
\text { Permission, Giving Instructions }\end{array}$ \\
\hline How & $\begin{array}{l}\text { Anticipatory Interactions, Applying Pre-Task } \\
\text { Knowledge, "watching what's going on", } \\
\text { Updating, Confirming, Information Artifact } \\
\text { Creating Situation Awareness, "Deciding } \\
\text { Individual Action Based on Information Given } \\
\text { by Others", "Deciding Individual Action by } \\
\text { Checking Common Information Artifact", } \\
\text { Information Transfer Across Communities, } \\
\text { "Knowledge about other's way of working", } \\
\text { Mechanism for Creating Information } \\
\text { Awareness, Sharing Information, "Providing } \\
\text { Required Information at right time", } \\
\text { Requesting Information, Taking Initiative to } \\
\text { Inform Other's "it is sensible you do", } \\
\text { Informing Related Personnel, Verbal } \\
\text { Notification, Verbally Concurring Course of } \\
\text { Action, Verifying Information Precision, } \\
\text { Making Changes to Common Information } \\
\text { Artifact }\end{array}$ \\
\hline Consequence & Deciding When? \\
\hline
\end{tabular}




\subsection{Making Informed Decisions}

The next category being presented here is that of "Making Informed Decisions. This phenomenon was found to be central to decision making during Handling Dynamic Nature of Work, which is reflected in the number of codes (61) forming this category.

This is particularly important while actors endeavor to Manage Time Constraint, while Helping Others, Exerting Authority over tasks and actions to be performed in the work process by others, while making Task Handover Decisions, and while having to "change(ing) the plan quickly" is response to the changing needs of the work environment.

The need for "Making Informed Decisions" occurs to aid personnel to Adapt to Change in Situation, to Cater to Others Requirements in the Work Process, and to Optimize Task Performance individually and collectively which encompasses Deciding Course of Action. The way this phenomenon occurs is mostly by Information Transfer_Across Work Communities. In the matrix, answering the question How identifies the different ways in which this is achieved. The consequence of "Making Informed Decisions" with respect to collaboration among heterogeneous work communities is Deciding When?, which is discussed in the next section.

Table 4. Conditional Relationship Guide of Category: Deciding When?

\begin{tabular}{|c|c|}
\hline Category & Deciding When? \\
\hline What & $\begin{array}{l}\text { Decision about when to perform actions and } \\
\text { tasks. This refers to both situation and time. } \\
\text { "the tower (tower controller) once they know } \\
\text { taxiway delta is clear will give him (departing } \\
\text { aircraft pilot) clearance to take-off" }\end{array}$ \\
\hline When & $\begin{array}{l}\text { Handling Dynamic Nature of Work, Managing } \\
\text { Time Critical Nature of Work }\end{array}$ \\
\hline Where & $\begin{array}{l}\text { Catering to Other's Requirements, Helping } \\
\text { Others, Response to Requests, Decision Based } \\
\text { on Situation, Sharing Responsibility, } \\
\text { Interaction with Other Work Communities, } \\
\text { "changing the plan quickly", Deciding Priority } \\
\text { of Action, Deciding Course of Action }\end{array}$ \\
\hline Why & $\begin{array}{l}\text { Catering to Other's Requirements, Task } \\
\text { Handover Decisions, Deciding Individual } \\
\text { Action Communication between Work } \\
\text { Communities, Giving Instructions, Giving } \\
\text { Permission, Handling Multiple Requests for } \\
\text { Same Action Made Simultaneously, Making } \\
\text { Changes to Common Information Artifact, } \\
\text { Sharing Information, Information } \\
\text { Transfer_Across Communities, }\end{array}$ \\
\hline How & $\begin{array}{l}\text { Comprehension, "Making } \\
\text { Decisions" }\end{array}$ \\
\hline Consequence & $\begin{array}{l}\text { Adapting to Change in Situation, Managing } \\
\text { Time Dependency, Managing Information } \\
\text { Dependency }\end{array}$ \\
\hline
\end{tabular}

\subsection{Deciding When?}

This category was found to be another important factor in the collaborative working of heterogeneous work communities especially while addressing the time critical and dynamic nature of the work environment. Decisions have to be made about the temporality of actions and tasks to be performed in order to efficiently coordinate the working of personnel belonging to different work communities. For example, decisions have to made as to when to handover tasks to personnel in another work community, when to send required information, when to respond to requests, when to give instructions etc. Making Informed Decisions plays a crucial role in Deciding When?. Managing Time Dependency and Managing Information Dependency were found to be the consequences of this aspect of decision making along with Adapting to Change in Situation.

\section{DISCUSSION}

The three main phenomena discussed here were found to be an integral part of the collaborative decision making process. The three categories of "Situated Decision Making", "Making Informed Decisions" and "Deciding When?" are three important processes among others involved in managing various dependencies that arise among heterogeneous work communities, as depicted in Figure 1. These processes do not operate discretely but in close connection with each other. The dynamics of the operation of these processes together help personnel in different work communities to work collaboratively.

From the onset of this investigation the perspective adopted towards decision making was more inclined to explore its social nature rather than the typical cognitive aspect of it, which is reflected in the discussion presented in the previous section. Employing the Grounded Theory approach has illuminated a different aspect towards the conceptualization of CIS pertaining to heterogeneous work communities. The investigation began with the aim of exploring collaborative decision making in a safety critical environment to inform the conceptualization of CIS. While employing the techniques prescribed by Grounded Theory methodology; by neutral questioning of data while generating codes, the researcher identified the phenomenon: managing interdependencies. During theoretical coding the relation between the two processes of decision making and managing dependencies came to the forefront. This has narrowed the focus of the investigation to exploring collaborative decision making to manage dependencies in heterogeneous work communities.

\section{CONCLUSION}

In this research we are endeavoring to contribute to the development of the notion of Common Information Space (CIS) by taking a Grounded Theory approach to the investigation. We have presented an example illustration of the methodology adopted towards the development of the notion CIS. This is done by discussing a fragment of one aspect of the investigation, that of decision making. The categories discussed in the above section illustrate the approach adopted for theory construction and the way it has been adapted to the investigation. Such an analytical approach is intended to provide a concrete foundation to the theory development by allowing theoretical constructs to emerge from field data.

The contribution of this work is twofold. One is the research that has been pursued by various investigators towards the development of the notion of CIS has been predominantly through ethnographic studies and drawing inferences based on these studies. However, not much focus has been given to the process between these two stages in the literature. We attempt to focus on the phase between the studies of workplaces and the notion of CIS derived by bringing in a systematic rigorous approach to the analysis process. The second contribution is the way in which Grounded Theory can be adapted to such an investigation. We have presented an integrated approach to 
facilitate the interpretive process involved in such qualitative studies. The contribution of this paper is intended to be at the analytical level to provide a frame for understanding and organizing relationships between the various elements of collaborative work.

\section{ACKNOWLEDGMENTS}

Our thanks to Dr. Paola Amaldi for her guidance and feedback while writing this paper. We would also like to thank the reviewers of the conference for their valuable feedback and suggestions.

\section{REFERENCE}

[1] Boland, J., Richard, J., Maheshawarl, K.A., et al. 1992. Sharing Perspectives in Distributed Decision Making. In Proceedings of the Conference on Computer Supported Cooperative Work (Toronto, Canada, October 31 - November 4, 1992).CSCW'92. $\mathrm{ACM}$

[2] Bossen, C. 2002. The Parameters of Common Information Spaces: the Heterogeneity of Cooperative Work at a Hospital Ward. In CSCW' 02 (New Orleans, Louisiana, USA, Nov 16-20, 2002).The Parameters of Common Information Spaces: the Heterogeneity of Cooperative Work at a Hospital Ward. ACM,176-185.

[3] Schmidt, K. and Bannon, L. 1992. "Taking CSCW Seriously: Supporting Articulation Work." Computer Supported Cooperative Work (CSCW): An International Journal. 1, 1 (June 22,1992), 7-40.

[4] Bannon, L.J. and Bødker, S. 1997. Constructing common information spaces. In Proceedings of the Fifth European Conference on Computer-Supported Cooperative Work (Lancaster, U.K. Dordrecht, Sep 7-11, 1997).ECSCW'97. Kluwer Academic Publishers, 81-96.

[5] Bannon, L.J. 2000. Understanding Common Information Spaces in CSCW. In Proceedings of the Workshop on Common Information Spaces (Copenhagen, Aug 23-25, 2000).Understanding Common Information Spaces in CSCW. http://www.itu.dk/people/schmidt/ciscph2000/Banno n.pdf

[6] Randall, D. 2000. What's Common about Common Information Spaces? . In Proceedings of the Workshop on Cooperative Organization of Common Information Spaces (Technical University of Denmark, 2000).What's Common about Common Information Spaces?

http://dmm.cti.dtu.dk/position/randall.pdf

[7] Bertelsen, W.O. and Bodker, S. 2001. Cooperation in massively distributed information spaces. In Proceedings of the Seventh European Conference on Computer Supported Cooperative Work (Bonn, Germany, Sep 16-20, 2001).ECSCW'07. Kluwer Academic Publishers,1-17.

[8] Reddy, M., Dourish, P., and Pratt, W. 2001. Coordinating Heterogeneous Work: Information and Representation in Medical Care. In Proceedings of the Seventh European Conference on Computer
Supported Cooperative Work (Bonn, Germany, Sep 16-20, 2001).ECSCW'01. Kluwer Academic Publishers, 239-258.

[9] Bossen, C. 2002. The Parameters of Common Information Spaces: the Heterogeneity of Cooperative Work at a Hospital Ward. In Proceedings of the Conference on Computer Supported Cooperative Work (New Orleans, Louisiana, USA, November 16-20, 2002).CSCW' 02. ACM,176-185.

[10] Fields, B., Amaldi, P., and Tassi, A. 2004. "Representing Collaborative Work: The Airport as Common Information Space." Cognition, Technology and

Work.2004)http://www.cs.mdx.ac.uk/staffpages/bobf/ papers/ATC-paper-v15.pdf.

[11] Rolland, H.K., Hepso, V., and Monteiro, E. 2006. Conceptualizing Common Information Spaces Across Heterogeneous Contexts: Mutable Mobiles and Sideeffects of Integration. In Proceedings of the Conference on Computer Supported Cooperative Work (Banff, Alberta, Canada, November 4-8, 2006).CSCW'06. ACM,493-500 http://www.idi.ntnu.no/ ericm/fp339-rolland.pdf

[12] Munkvold, G. and Ellingsen, G. 2007. Common Information Spaces along the illness trajectories of chronic patients. In Proceedings of the Tenth European Conference on Computer Supported Cooperative Work (Limerick, Ireland, September 2428, 2007).ECSCW'07. Springer 2007,291-310.

[13] Glaser, B.G. and Strauss, A. 1967 The Discovery of Grounded Theory: Strategies for Qualitative Research, Aldine New York.

[14] Glaser, B.G. 1978 Theoretical Sensitivity. Advances in the Methodology of Grounded Theory. Mill Valley, California, The Sociology Press.

[15] Strauss, A. and Corbin, J. 1990 Basics of Qualitative Research: grounded theory procedures and techniques. London, Sage.

[16] Hunter, K., Hari, S., Egbu, C., et al. 2005. "Grounded Theory: Its Diversification and Application Through two Examples From Research Studies on Knowledge and Value Management." The Electronic Journal of Business Research Methodology. 3, 1 2005),57-68. http://www.univie.ac.at/Wissenschaftstheorie/peschl/I va/cogscise uni/ws04/docs/Hutchins\%20Cockpit.pdf.

[17] Glaser, B.G. 1992 Basics of Grounded Theory Analysis: Emergence vs. Forcing. Mill Valley, California, Sociology Press.

[18] Scott, W., Karen 2004. "Relating Categories in Grounded Theory Analysis: Using a Conditional Relationship Guide and Reflective Coding Matrix." The Qualitative Report. 9, 1 (March,2004),113-126.

[19] Strauss, A. and Corbin, J. 1998 Basics of Qualitative Research: Grounded theory procedures and techniques. Newbury Park, California, Sage.

[20] Crowston, K., A Taxonomy of Organizational Dependencies and Coordination Mechanisms (Working paper No. 3718-94):. 1994: Massachusetts Institute of Technology, Sloan School of Management. 